\title{
Quantitative analysis of N-terminal valine peptide adducts specific for 1,2-epoxy-3-butene
}

\author{
Nadia I. Georgieva*, Gunnar Boysen, Patricia B. Upton, Karupiah Jayaraj, Avram Gold, and \\ James A. Swenberg \\ Department of Environmental Sciences and Engineering, The University of North Carolina, Chapel \\ Hill, NC, United States
}

\begin{abstract}
Butadiene (BD) metabolism shows gender, species and concentration dependency, making the extrapolation of animal results to humans complex. BD is metabolized mainly by cytochrome $\mathrm{P} 450$ 2E1 to three epoxides, 1,2-epoxy-3-butene (EB), 1,2;3,4-diepoxybutane (DEB) and 1,2-epoxybutanediol (EB-diol). For accurate risk assessment it is important to elucidate species differences in the internal formation of the individual epoxides in order to assign the relative risks associated with their different mutagenic potencies. Analysis of $\mathrm{N}$-terminal globin adducts is a common approach for monitoring the internal formation of BD derived epoxides. Our long term strategy is to develop an LC-MS/MS method for simultaneous detection of all three BD hemoglobin adducts. This approach is modeled after the recently reported immunoaffinity LC-MS/MS method for the cyclic $N, N$-(2,3-dihydroxy-1,4-butadyil)-valine ( $p y r$-Val, derived from DEB). We report herein the analysis of the EB-derived 2-hydroxyl-3-butenyl-valine peptide (HB-Val). The procedure utilizes trypsin hydrolysis of globin and immunoaffinity (IA) purification of alkylated heptapeptides. Quantitation is based on LC-MS/MS monitoring of the transition from the singly charged molecular ion of HBVal (1-7) to the $a_{1}$ fragment. Human HB-Val (1-11) was synthesized and used for antibody production. As internal standard, the labeled rat $-\left[{ }^{13} \mathrm{C}_{5}{ }^{15} \mathrm{~N}\right]-\mathrm{Val}(1-11)$ was prepared through direct alkylation of the corresponding peptide with EB. Standards were characterized and quantified by LC-MS/MS and LC-UV. The method was validated with different amounts of human HB-Val standard. The recovery was $>75 \%$ and coefficient of variation $<25 \%$. The LOQ was set to $100 \mathrm{fmol} /$ injection. For a proof of principal experiment, globin samples from male and female rats exposed to $1000 \mathrm{ppm} \mathrm{BD}$ for 90 days were analyzed. The amounts of HB-Val present were $268.2 \pm 56$ and 350 $\pm 70 \mathrm{pmol} / \mathrm{g}$ (mean \pm S.D.) for males and females, respectively. No HB-Val was detected in controls. These data are much lower compared to previously reported values measured by GC-MS/MS. The difference may be due higher specificity of the LC-MS/MS method to the N-terminal peptide from the $\alpha$-chain versus derivatization of both $\alpha$ - and $\beta$-chain by Edman degradation, and possible instability of HB-Val adducts during long term storage (about 10 years) between the analyses. These differences will be resolved by examining recently collected samples, using the same internal standard for parallel analysis by GC-MS/MS and LC-MS/MS. Based on our experience with pyrVal adduct assay we anticipate that this assay will be suitable for evaluation of $\mathrm{HB}-\mathrm{Val}$ in multiple species.
\end{abstract}

\section{Keywords}

Butadiene; Protein adducts 


\section{Introduction}

1,3-Butadiene (BD) is an important industrial chemical used in the production of synthetic rubber that is also found in gasoline, cigarette smoke, and auto exhaust [1]. Epidemiologic studies have shown an increased incidence of leukemia in workers exposed to BD in synthetic rubber production [2] and an increase in lymphohematopoietic cancers in BD production workers [3]. The NTP and US EPA have categorized BD as carcinogenic to humans by inhalation, while IARC classifies BD as a probable human carcinogen [4-6]. It has clearly been demonstrated that $\mathrm{BD}$ is a multi-species, multi-site carcinogen in rodents, with mice being a much more sensitive species than rats $[4,7-11]$.

BD metabolism is gender, species and concentration dependent. This makes the extrapolation of animal results to humans complex. The electrophilic metabolites of BD are 1,2-epoxy-3butene (EB), 1,2;3,4-diepoxybutane (DEB), and 1,2-epoxy-3,4-butanediol (EB-diol) (Scheme 1). They exhibit significantly different mutagenicity, with DEB being 100- and 200-fold more mutagenic than EB and EB-diol, respectively. Therefore it is important to elucidate the internal formation of the individual epoxides in order to assign their relative importance in mutagenesis and carcinogenesis. The formation of protein adducts as surrogate markers for exposure has been widely accepted. Methods have been established to monitor exposure to occupational toxins, carcinogens and to tobacco specific carcinogens [12]. Hemoglobin ( $\mathrm{Hb})$ and serum albumin adducts are used most widely, because they have the advantages of being readily accessible, accumulate over the life time of the protein (60 days for rat erythrocytes) and, unlike DNA adducts, are not repaired. In addition to exposure assessments, the use of protein adducts was recently reported for studying different metabolic pathways in vivo [13], an important issue for BD.

The protein adducts formed by EB, DEB and EB-diol are 2-hydroxyl-3-butenyl-valine (HBVal), $N, N$-(2,3-dihydroxy-1,4-butadyil)-valine ( $p y r$-Val) and 2,3,4-trihydroxy butyl-valine (THB-Val), respectively. These $\mathrm{N}$-terminal valine adducts have been previously used as biomarkers for the internal formation of the corresponding epoxides. Up to now, both HB-Val and THB-Val adducts in rodents and humans only had been measured by GC-MS/MS, a procedure based on the modified Edman degradation method of Törnqvist et al. [14]. A novel LC-MS/MS method for analysis of pyr-Val was developed [15-17] and substantially improved in the matter of sample purification by immunoaffinity chromatography (IA) and detection sensitivity by capillary LC-ESI-MS/MS [13]. This allowed the measurement of the cyclic adduct, $p y r$-Val, in a wide range of $\mathrm{BD}$ exposed samples from mice and rats, ranging from concentrations as low as $1 \mathrm{ppm} \mathrm{BD} \mathrm{[18]} \mathrm{to} 1250 \mathrm{ppm}$ BD. Here we report the development of a similar method for the analysis of the EB specific HB-Val adduct in rats, as an incremental step to our overall goal to develop a method for simultaneous analysis of all three BD-derived $\mathrm{N}$-terminal valine adducts by LC-MS/MS.

\section{Materials and methods}

Materials. Trypsin (biotin-agarose, from bovine pancreas) was purchased from Sigma-Aldrich (St. Louis, MO). All reagents and solvents were ACS grade or higher. Centricon 3 filters were obtained from Amicon Inc. (Beverly, MA) and Microspin filter tubes (regenerated cellulose, $0.2 \mathrm{um}$ ) were from Alltech Associates Inc. (Deerfield, IL). Polyclonal antibodies against HBVal (1-11) were raised by Anaspec (San Jose, CA) using peptides synthesized as described below.

\subsection{Synthesis of standard peptides}

The N-terminal $\alpha$-chain peptide for human HB-VLSPADKTNVC (human HB-Val (1-11) standard) was synthesized based on the procedure described previously [19] and used for 
antibody production (see below). The stable isotope-labeled rat internal standard peptide (HB$\left[{ }^{13} \mathrm{C}_{5}{ }^{15} \mathrm{~N}\right]$ VLSADDKTNIK peptide) was synthesized for accurate quantitation, by direct alkylation of the non-adducted $\left[{ }^{13} \mathrm{C}_{5}{ }^{15} \mathrm{~N}\right]$-labeled rat $(1-11)$ peptide with $\mathrm{EB}$ at molar ratio of 1:25, in water, $\mathrm{pH} 8.0$, at $37^{\circ} \mathrm{C}$ for $42 \mathrm{~h}$ according to Fred et al. [15]. The corresponding HBVal (1-7) peptides were prepared from (1-11) peptides by trypsin hydrolysis as described below. For the analysis of the rat samples 12 pmol internal standard was added prior to trypsin hydrolysis.

\subsection{Immunoaffinity chromatography}

Polyclonal antibodies were raised against the human HB-Val (1-11) peptide, in which the Cterminal lysine was substituted by cysteine to allow antibody production as described [13]. Immunoaffinity columns were prepared essentially according to Ham et al. [20].

\subsection{Animals and exposures}

Globin samples were available from male and female Sprague Dawley rats, 22 days of age, exposed to $1000 \mathrm{ppm}$ BD for 90 days at the Haskell Laboatory for Toxicology and Industrial Medicine at DuPont (Newark, DE) [21]. All animals were sacrificed within $2 \mathrm{~h}$ post-exposure by exsanguination under $\mathrm{CO}_{2}$ anesthesia. Blood samples were collected by cardiac puncture. Red blood cells were isolated, washed twice with $0.9 \%$ saline, and stored at $-80^{\circ} \mathrm{C}$.

\subsection{Globin isolation and trypsin hydrolysis}

Globin was isolated according the protocol of Mowrer et al. [22] and processed as described elsewhere [13]. Briefly, globin (about $20 \mathrm{mg}$ ) was dissolved in $0.1 \mathrm{M} \mathrm{NH}_{4} \mathrm{HCO}_{3}, \mathrm{pH} 8.0$, containing 12 pmol rat HB-Val internal standard and was digested with trypsin-biotin-agarose enzyme suspension at $37^{\circ} \mathrm{C}$ for $20 \mathrm{~h}$ (shaking). The resulting peptide mixture was passed through Centricon 3 filters and the HB-Val peptides were isolated by anti-HB-Val IA chromatography. HB-Val (1-7) peptides were eluted in 5\% formic acid, filtered through Microspin $(2 \mu \mathrm{m})$ columns and stored at $-20^{\circ} \mathrm{C}$ until analyzed by UPLC-MS/MS.

\subsection{Quantitative analysis of HB-Val adduct}

The quantitative analysis of the HB-Val (1-7) peptides by LC-ESI-MS/MS was performed with an UPLC (Waters, Milford, MS) coupled to a TSQ-Quantum triple quad mass analyzer (ThermoFinnigan, San Jose, CA). A $1.0 \mathrm{~mm} \times 100 \mathrm{~mm}$ UPLC $^{\text {TM }}$ BEH C ${ }_{18}, 1.7 \mu \mathrm{m}$ column was operated with a linear gradient of 5\% methanol-15 mM ammonium formate, $\mathrm{pH} 2.7$, for $0.3 \mathrm{~min}$ then to $95 \%$ methanol-15 mM ammonium formate, $\mathrm{pH} 2.7$, in $1 \mathrm{~min}$, at a flow rate of $75 \mu \mathrm{l} / \mathrm{min}$. The HB-Val retention times were determined with HB-(1-7) peptide standards. The peptides were detected in single reaction monitoring (SRM) mode, monitoring the transition of the singly charged ions to the $\mathrm{a}_{1}$-fragments $(\mathrm{m} / \mathrm{z} 799 \rightarrow 142,817 \rightarrow 142$ and $823 \rightarrow 147$ for human analyte, rat analyte and rat internal standard, respectively). The MS conditions were as follows: spray voltage $2200 \mathrm{~V}$, heated capillary temperature $350^{\circ} \mathrm{C}$. The immunoaffinity purified samples were reconstituted in $20 \mu \mathrm{l}$ of water and $1 \mu \mathrm{l}$ injected.

\section{Results and discussion}

The analysis of HB-Val and THB-Val by modified Edman degradation and subsequent analysis by GC-MS/MS revealed important insights into species and exposure concentration differences in BD metabolism. These previous studies highlighted the need for determination of pyr-Val, which has been demonstrated recently by a peptide-LC-MS/MS approach [13], to understand the role of the different epoxides in mutagenesis and carcinogenesis following exposure to $\mathrm{BD}$. The later methodology is less time consuming, more precise, highly specific to alkylations of the $\mathrm{N}$-terminus and to the analysis of other and possible multiple alkylations, 
simultaneously. The goal of this report was to establish a peptide method for the detection of $\mathrm{HB}-\mathrm{Val}$, as an initial step towards a method for the simultaneous analysis of several BD derived $\mathrm{N}$-terminal adducts.

The strategy of the method presented herein is based on trypsin digestion and isolation of the alkylated N-terminal heptapeptide by IA chromatography prior to quantitation by LC-MS/MS. Therefore, the human HB-Val (1-11) was synthesized and used to raise polyclonal anti-HBVal antibodies. A fraction of HB-Val (1-11) was converted to HB-Val (1-7) by trypsin hydrolysis and utilized for instrument optimatization. In addition, for accurate quantitation, stable isotope labeled rat $\mathrm{HB}-\left[{ }^{13} \mathrm{C}_{5}{ }^{15} \mathrm{~N}\right] \mathrm{Val}(1-11)$ was prepared as internal standard by reaction of EB with $\left[{ }^{13} \mathrm{C}_{5}{ }^{15} \mathrm{~N}\right]$-valine labeled (1-11) peptide. The (1-7 and 1-11) standards and internal standards were characterized by tandem mass spectrometry sequencing (Fig. 1) using an LCQ-Deca ion trap mass analyzer (ThermoFinnigan, San Jose, CA) and the accurate mass for the internal standard peptide was 823.44458 (expected 823.44398) as determined on an 12-T FT-MS. The concentration of the human analyte standard used for MS-tuning, optimization and method validation was determined by weight, and the amount of HB-Val in the internal standard mixture was quantitated by UPLC-MS/MS versus the human HB-Val (1-7), and by LC-UV versus the corresponding non-alkylated rat peptide according to [15]. The values obtained by both methods for rat HB-Val (1-7) internal standard were 240 and 200 $\mathrm{pmol} / \mu \mathrm{l}$, respectively $(220 \pm 20$ mean $\mathrm{pmol} / \mu \mathrm{l})$.

Antibodies raised against the human peptide were used to produce IA columns for sample purification, because our long term goal is to study BD metabolism in exposed humans. Control globin was spiked with different amounts of analyte and internal standard peptides to determine assay recovery and reproducibility (data not shown). Similar to our previous experience with pyr-Val, IA columns prepared with serum from the second bleeding (8 weeks post immunization) had better recovery compared to columns prepared with serum from the first bleeding ( $75 \%$ versus $15 \%)$, based on amounts of internal standard loaded initially and detected. The results also demonstrated that the polyclonal antibodies raised against the human HB-Val (1-11) had equal affinity to the rat HB-Val (1-7).

Before the measurement of in vivo samples, the precision and accuracy of the method were tested, as well as the recovery on the IA columns. The coefficient of variation (CV) was $<25 \%$ and the recovery was $>75 \%$. For instrument calibration and demonstration of linearity, a calibration curve ranging from 50 to $500 \mathrm{fmol} / \mu \mathrm{l}$ was generated using the human $\mathrm{HB}-\mathrm{Val}$ (17) standard and rat $\left[{ }^{13} \mathrm{C}_{5}{ }^{15} \mathrm{~N}\right] \mathrm{HB}-\mathrm{Val}(1-7)$ internal standard (Fig. 2). From these calibration solutions the LOQ was set to $100 \mathrm{fmol}$ on column. Signal to noise ratio was determined within the peaks and signals had to have a minimum of 14 points over the peak to be considered detected. For the in vivo measurements, $\sim 20 \mathrm{mg}$ of globin from rats exposed by inhalation to 0 (three females) or $1000 \mathrm{ppm} \mathrm{BD}$ (six males and six females) for 90 days were analyzed for $\mathrm{HB}-\mathrm{Val}$. A representative chromatogram from a male rat (22 $\mathrm{mg}$ globin used) is shown in Fig. 3 . The values found were $268 \pm 56$ and $350 \pm 70 \mathrm{pmol} / \mathrm{g}$ globin for males and females, respectively. This difference, however, was not statistically significant according to the $t$-test. Female rats formed 1.3-fold more HB-Val compared to males (Fig. 4), a ratio that is close to 1.58 reported previously [23].

The amounts detected in the present study were about 24-fold lower compared to the analysis of the same samples previously by GC-MS/MS [23]. To exclude the possibility that the antibody used may have been raised against the minor $\mathrm{C}-2$ regioisomer of $\mathrm{HB}-\mathrm{Val}$, the human (1-11) standard used for antibody production was further characterized by HSQC- and HMBCNMR in $\mathrm{D}_{2} \mathrm{O}$. These analyses confirmed the presence of only the $\mathrm{C}-1$ regioisomer $\mathrm{HB}-\mathrm{Val}$ (data not shown). To explore the possible cause of the different results, we are analyzing recently collected globin samples by LC-MS/MS and GC-MS/MS in parallel, using the 
internal standard from the peptide method. This experiment will show whether the differences were caused by the methods or due to sample handling or storage (different methods conducted more than 10 years apart). At this time the reasons for the difference are unknown and could be due to: (1) the use of $\left[{ }^{2} \mathrm{H}_{6}\right]$-EB alkylated globin as internal standard for GC-MS/MS, which meanwhile has been shown to be unstable, versus a newly synthesized internal standard peptide for LC-MS/MS, (2) higher specificity of the new assay to the N-terminal peptide from the globin $\alpha$-chain only, with no quantitation of the $\beta$-chain, and (3) possible degradation of HBVal during the storage period (over 10 years) between the analyses.

In addition to the formation of N-terminal valine adducts, it has been reported that $\mathrm{EB}$ and DEB also alkylate lysine, histidine, serine and methionine residues in the hemoglobin $\alpha$ - and $\beta$-chain [24-27]. It has to be emphasized that these in vitro studies were performed to qualitatively identify possible binding sites and were carried out at high molar ratios of EB (or DEB) to protein, far different from the exposures encountered in vivo. While these residues may be more reactive, the analysis of alkylation at one site has the advantage that no corrections have to be made for accessibility and affinity of species specific individual residues towards the different BD derived epoxides.

In conclusion, a new method for quantitation of EB derived HB-Val adduct has been established. The data presented demonstrate excellent reproducibility with a $\mathrm{CV}<25 \%$ per group $(n=5)$ and suitability for studying the internal formation of EB in vivo. The data are qualitatively in agreement with previous analyses by GC-MS/MS, however the values are about 24-fold lower. Further validation is underway to determine the source of this difference and standardize the procedure so that comparable data are obtained with GC-MS/MS and LCMS/MS. Future focus will be to extend this technology by preparing IA columns that contain multiple antibodies to allow analysis of HB-Val, pyr-Val and THB-Val simultaneously.

\section{Abbreviations}

BD, 1,3-butadiene; BD-diol, 3-butene-1,2-diol; CV, coefficient of variation; DEB, 1,2 ;3,4diepoxybutane; EB, 1,2-epoxy-3-butene; EB-diol, 1,2-epoxy-3,4-butanediol; EH, Epoxide hydrolase; HB-Val, 2-hydroxy-3-butenyl-valine; pyr-Val, $N, N$-(2,3-dihydroxy-1,4-butadiyl) valine; THB-Val, 2,3,4-trihydroxybutyl-valine.

\section{Acknowledgments}

This research was supported in part by the American Chemistry Council and NIH grants R01 ES012689, P30 ES10126, R42 ES11746, F32 ES013107 and T32-ES07018.

\section{References}

1. ATSDR. Benzene, Agency for Toxic Substances and Disease Registery. U.S. Department of Health and Human Services, Public Health Service; 1992. Toxicological Profile for 1,3-Butadiene.

2. Delzell E, Sathiakumar N, Hovinga M, Macaluso M, Julian J, Larson R, Cole P, Muir DC. A followup study of synthetic rubber workers. Toxicology 1996;113:182-189. [PubMed: 8901897]

3. Divine BJ, Hartman CM. Mortality update of butadiene production workers. Toxicology 1996;113:169-181. [PubMed: 8901896]

4. HEI Report 92. Research Triangle Park, NC: U.S. Public Health Service, U.S. Department of Health and Human Services; 1984. Toxicology and carcinogenesis studies of 1,3-butadiene in B6C3F1 mice.

5. US EPA. Health assessment of 1,3-butadiene. 2002. Office or Research and Development, National Center for Environmental Assessment.

6. IARC. IARC monographs on the evaluation of carcinogenic risks to humans 1999:109-225. [PubMed: 10476446] 
7. Huff JE, Melnick RL, Solleveld HA, Haseman JK, Powers M, Miller RA. Multiple organ carcinogenicity of 1,3-butadiene in B6C3F1 mice after 60 weeks of inhalation exposure. Science 1985;227:548-549. [PubMed: 3966163]

8. Melnick RL, Huff J, Chou BJ, Miller RA. Carcinogenicity of 1,3-butadiene in C57B1/6Xc3H F1-mice at low exposure concentrations. Cancer Res 1990;50:6592-6599. [PubMed: 2208121]

9. Melnick RL, Huff JE, Roycroft JH, Chou BJ, Miller RA. Inhalation toxicology and carcinogenicity of 1,3-butadiene in B6C3F1 mice following 65 weeks of exposure. Environ. Health Perspect 1990;86:2736. [PubMed: 2401263]

10. Owen PE, Glaister JR, Gaunt IF, Pullinger DH. Inhalation toxicity studies with 1,3-butadiene. 3. Two year toxicity/carcinogenicity study in rats. Am. Ind. Hyg. Assoc. J 1987;48:407-413. [PubMed: 3591659]

11. Owen PE, Glaister JR. Inhalation toxicity and carcinogenicity of 1,3-butadiene in Sprague-Dawley rats. Environ. Health Perspect 1990;86:19-25. [PubMed: 2401255]

12. Törnqvist M, Fred C, Haglund J, Helleberg H, Paulsson B, Rydberg P. Protein adducts: quantitative and qualitative aspects of their formation, analysis and applications. J. Chromatogr. B: Anal. Technol. Biomed. Life Sci 2002;778:279-308.

13. Boysen G, Georgieva NI, Upton PB, Jayaraj K, Li Y, Walker VE, Swenberg JA. Analysis of diepoxide-specific cyclic N-terminal globin adducts in mice and rats after inhalation exposure to 1,3butadiene. Cancer Res 2004;64:8517-8520. [PubMed: 15574756]

14. Törnqvist M, Mowrer J, Jensen S, Ehrenberg L. Monitoring of environmental cancer initiators through hemoglobin adducts by a modified Edman degradation method. Anal. Biochem 1986;154:255-266. [PubMed: 3706730]

15. Fred C, Kautiainen A, Athanassiadis I, Törnqvist M. Hemoglobin adduct levels in rat and mouse treated with 1,2:3,4-diepoxybutane. Chem. Res. Toxicol 2004;17:785-794. [PubMed: 15206899]

16. Kautiainen A, Fred C, Rydberg P, Törnqvist M. A liquid chromatography tandem mass spectrometric method for in vivo dose monitoring of diepoxybutane, a metabolite of butadiene. Rapid Commun. Mass Spectrom 2000;14:1848-1853. [PubMed: 11006595]

17. Swenberg JA, Koc H, Upton PB, Georgieva N, Ranasinghe A, Walker VE, Henderson R. Using DNA and hemoglobin adducts to improve the risk assessment of butadiene. Chem. Biol. Interact 2001;135136:387-403.

18. Swenberg JA, et al. Chem. Biol. Interact. submitted for publication.

19. Jayaraj K, Georgieva NI, Gold A, Sangaiah R, Koc H, Klapper DG, Ball LM, Reddy AP, Swenberg JA. Synthesis and characterization of peptides containing a cyclic Val adduct of diepoxybutane, a possible biomarker of human exposure to butadiene. Chem. Res. Toxicol 2003;16:637-643. [PubMed: 12755593]

20. Ham AJL, Ranasinghe A, Morinello EJ, Nakamura J, Upton PB, Johnson F, Swenberg JA. Immunoaffinity/gas chromatography/high-resolution mass spectrometry method for the detection of $\mathrm{N}^{2}$,3-ethenoguanine. Chem. Res. Toxicol 1999;12:1240-1246. [PubMed: 10604874]

21. Bevan C, Stadler JC, Elliott GS, Frame SR, Baldwin JK, Leung HW, Moran E, Panepinto AS. Subchronic toxicity of 4-vinylcyclohexene in rats and mice by inhalation exposure. Fundam. Appl. Toxicol 1996;32:1-10. [PubMed: 8812199]

22. Mowrer J, Törnqvist M, Jensen S, Ehrenberg L. Modified edman degradation applied to hemoglobin for monitoring occupational exposure to alkylating-agents. Toxicol. Environ. Chem 1986;11:215231.

23. Swenberg, JA.; Christova-Gueorguieva, NI.; Upton, PB.; Ranasinghe, A.; Scheller, N.; Wu, KY.; Hayes, R. HEI Report 92. Cambridge, MA: 2000. 1,3-Butadiene: cancer, mutations, and adducts. Part V. Hemoglobin adducts as biomarkers of butadiene exposure and metabolism; p. 191-209.

24. Moll TS, Harms AC, Elfarra AA. A comprehensive structural analysis of hemoglobin adducts formed after in vitro exposure of erythrocytes to butadiene monoxide. Chem. Res Toxicol 2000;13:11031113. [PubMed: 11087432]

25. Basile A, Ferranti P, Pocsfalvi G, Mamone G, Miraglia N, Caira S, Ambrosi L, Soleo L, Sannolo N, Malorni A. A novel approach for identification and measurement of hemoglobin adducts with 1,2,3,4diepoxybutane by liquid chromatography/electrospray ionisation mass spectrometry and matrix- 
assisted laser desorption/ionisation tandem mass spectrometry. Rapid Commun. Mass Spectrom 2001;15:527-540. [PubMed: 11312501]

26. Miraglia N, Basile A, Pieri M, Acampora A, Malorni L, De Giulio B, Sannolo N. Ion trap mass spectrometry in the structural analysis of haemoglobin peptides modified by epichlorohydrin and diepoxybutane. Rapid Commun. Mass Spectrom 2002;16:840-847. [PubMed: 11948814]

27. Badghisi H, Liebler DC. Sequence mapping of epoxide adducts in human hemoglobin with LCtandem MS and the SALSA algorithm. Chem. Res. Toxicol 2002;15:799-805. [PubMed: 12067247] 

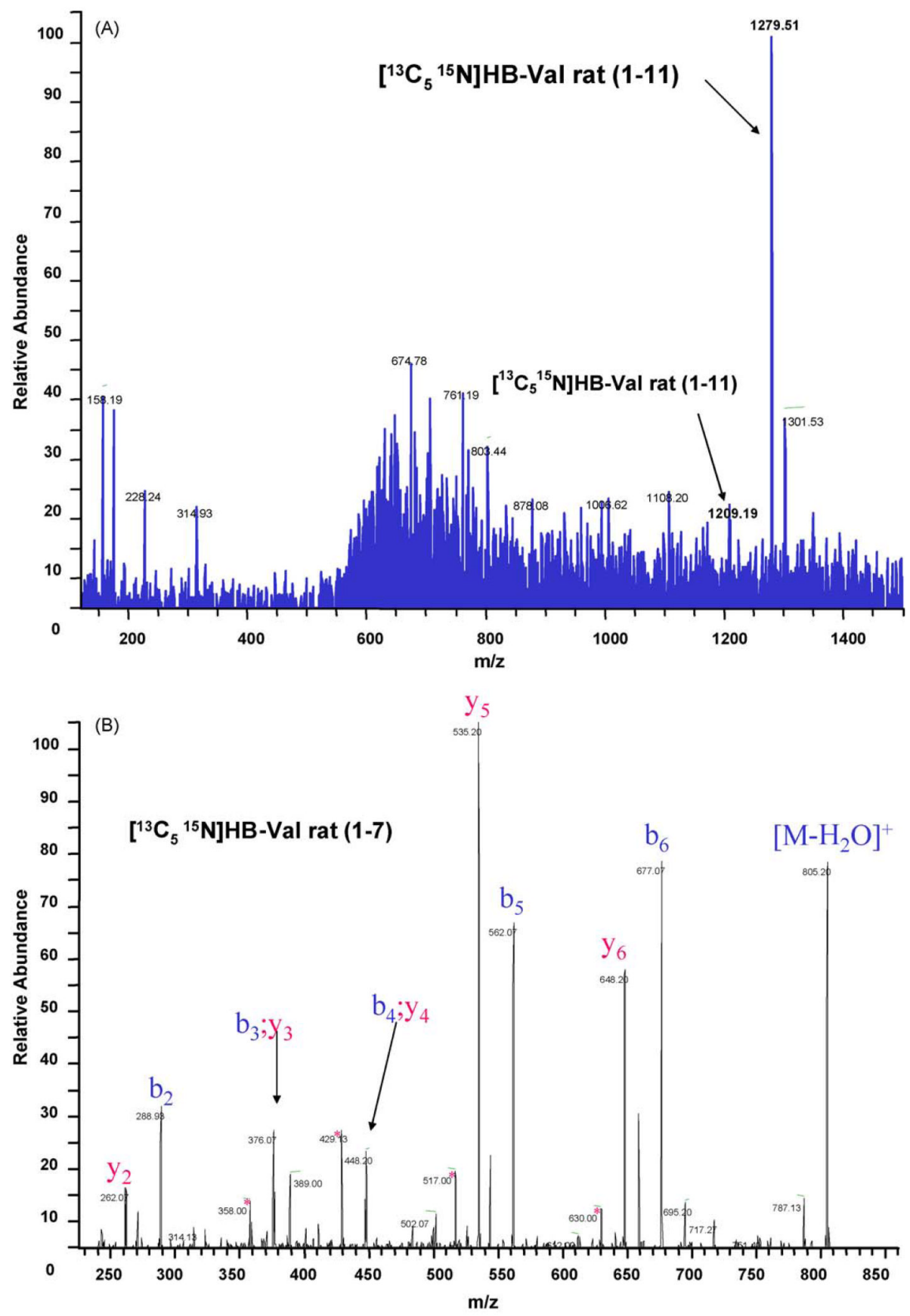

Fig. 1.

Characterization of rat $\left[{ }^{13} \mathrm{C}_{5}{ }^{15} \mathrm{~N}\right] \mathrm{HB}-\mathrm{Val}(1-11)$ and (1-7) internal standard peptide. (A) Full scan $(\mathrm{m} / \mathrm{z}, 100-1500)$ of rat $\left[{ }^{13} \mathrm{C}_{5}{ }^{15} \mathrm{~N}\right] \mathrm{HB}-\mathrm{Val}(1-11)$ and (B) MS/MS spectrum of rat $\left[{ }^{13} \mathrm{C}_{5}{ }^{15} \mathrm{~N}\right] \mathrm{HB}-$ Val $(1-7)$ 


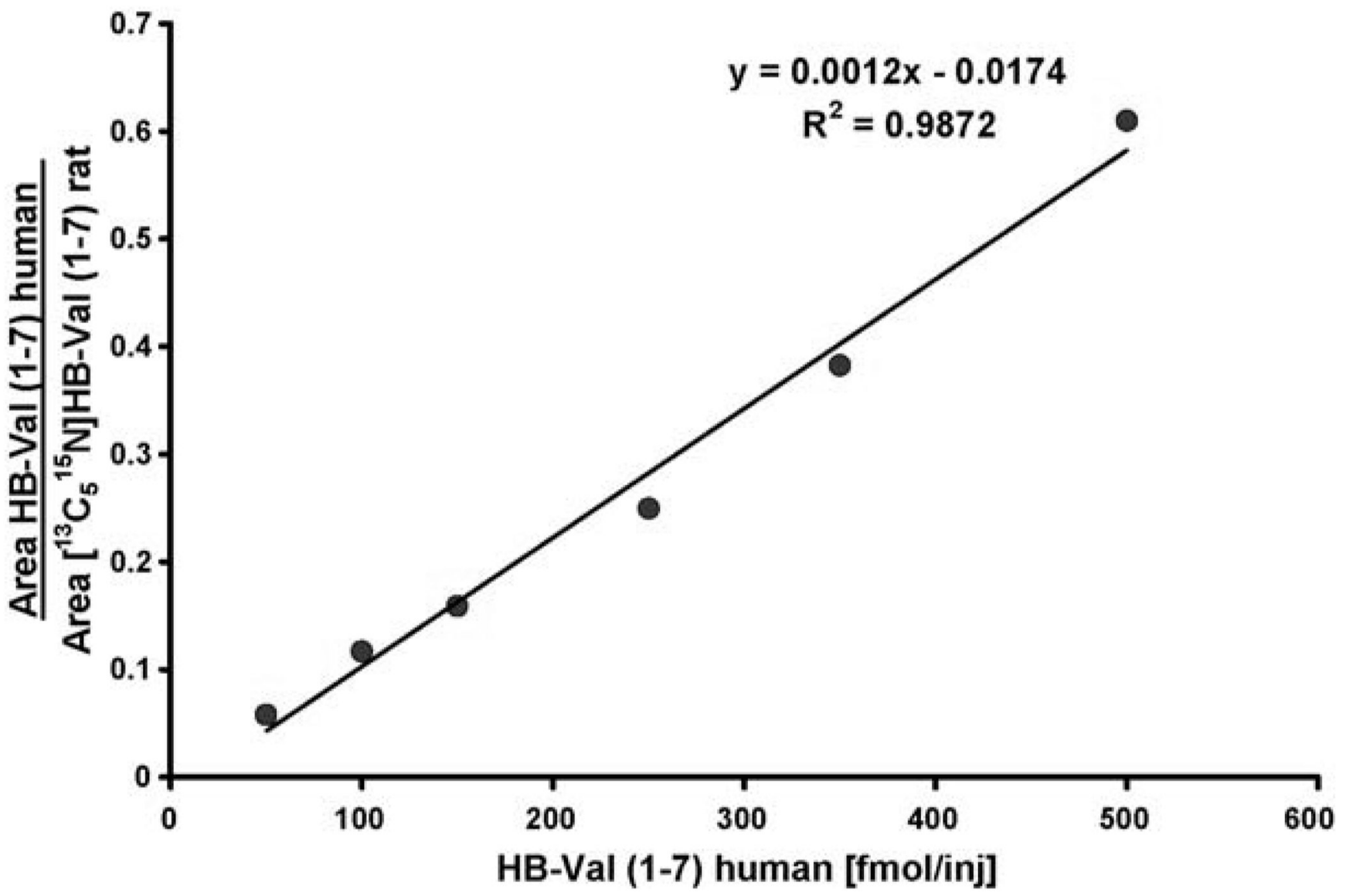

Fig. 2.

Calibration curve for HB-Val. 


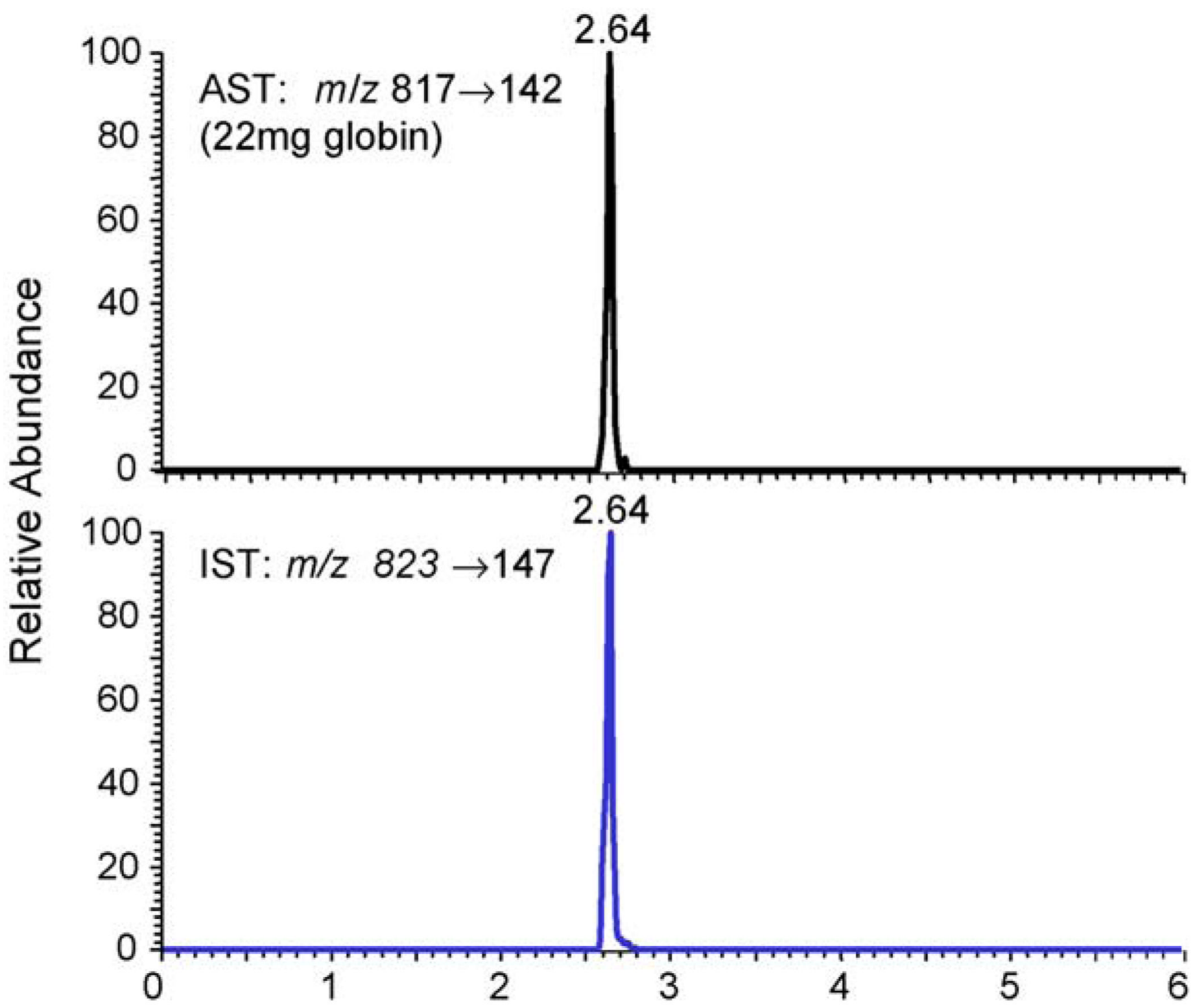

Fig. 3.

Ion-chromatogram of HB-Val peptide from a male rat exposed to $1000 \mathrm{ppm}$ BD for 90 days. Shown are the transitions of the analyte $(\mathrm{m} / \mathrm{z} 817 \rightarrow 142)$ and internal standard peptide $(\mathrm{m} / \mathrm{z}$ $823 \rightarrow 147$ ). 


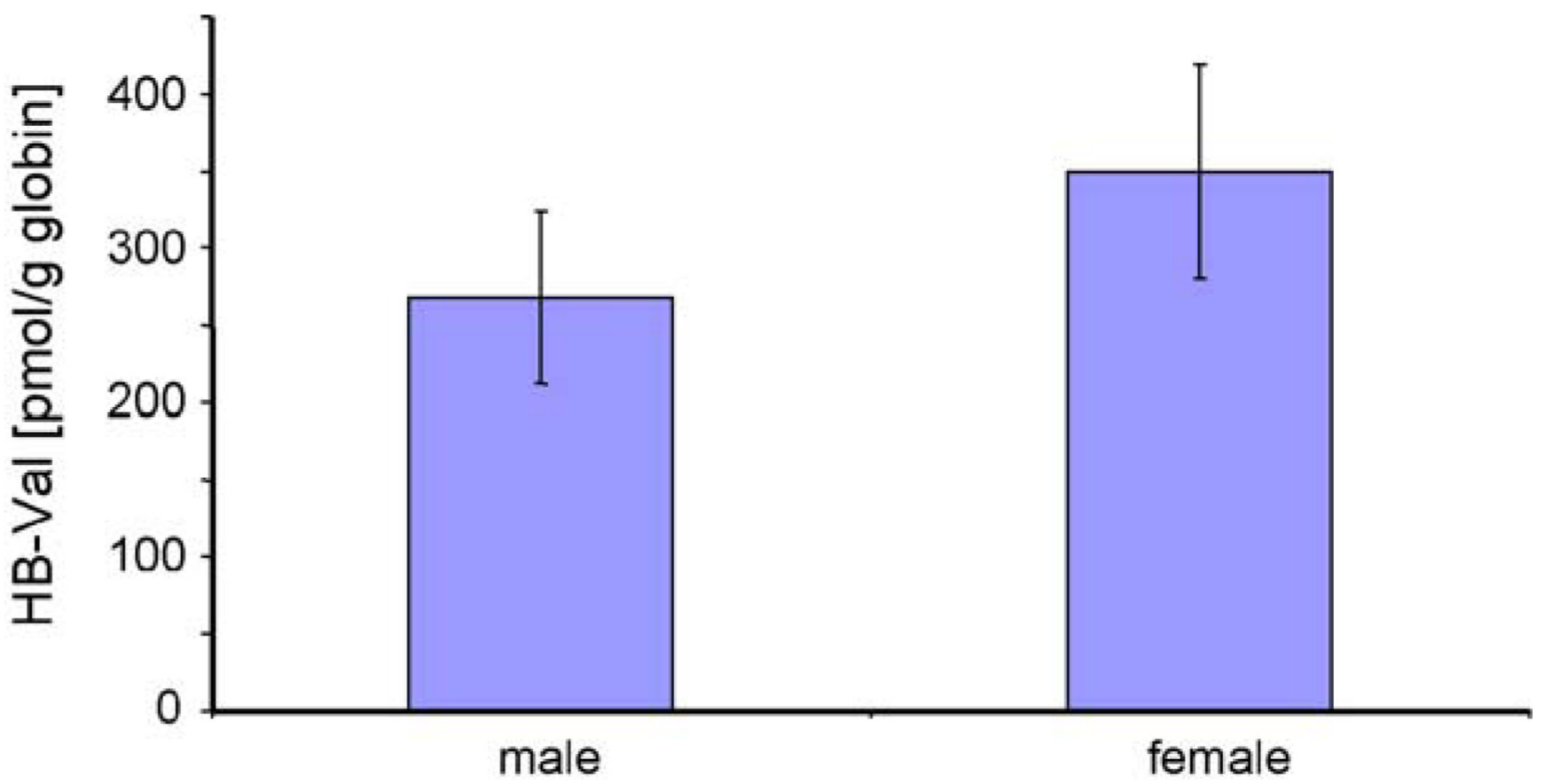

Fig. 4.

Comparison of HB-Val in male and female rats exposed to $1000 \mathrm{ppm}$ BD for 90 days (mean \pm S.D., $n=6$ ). 
<smiles>C=CC=C</smiles>

1,3-Butadiene (BD)

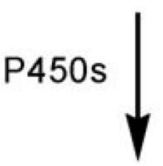<smiles>C=CC(O)CO</smiles>

3-Butene-1,2-diol (BD-diol)<smiles>C=CC1CO1</smiles><smiles></smiles><smiles>C1OC1C1CO1</smiles>

1,2-Epoxy-3-butene (EB)

1,2:3,4-Diepoxybutane (DEB)

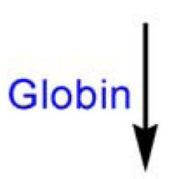

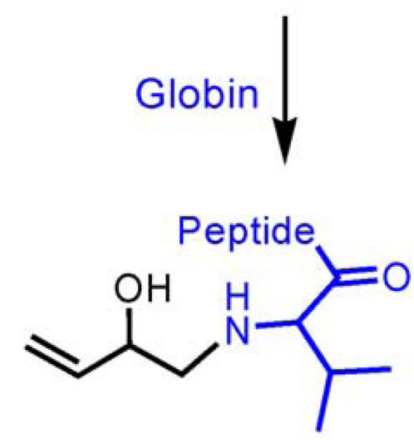

HB-Val<smiles>CC(C)C(C(=O)O)N1CC(O)C(O)C1</smiles>

pyr-Val

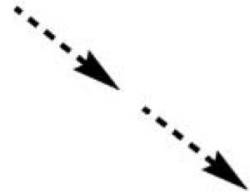

1,2-Epoxy-3,4-butanediol (EB-diol)

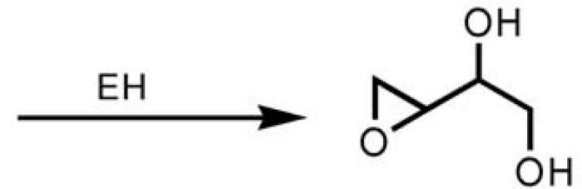

Globin $\downarrow$<smiles>CC(C)C(NCC(O)C(O)CO)C(=O)OCc1ccccc1</smiles>

THB-Val

Scheme 1.

BD metabolism and formation of globin adducts. 